\title{
Antimicrobial activity, toxicity and accumulated hard-tissue debris (AHTD) removal efficacy of several chelating agents
}

\author{
L. Giardino ${ }^{1}$ \\ A. Bidossi ${ }^{2}$, M. Del Fabbro 3,4 \\ P. Savadori ${ }^{4}$, M. Maddalone ${ }^{5}$, L. Ferrari $^{5}$, \\ N. V. Ballal 6 \\ S. Das $^{7}$ \& B. S. S. Rao \\ ${ }^{1}$ School of Dentistry, University of Catanzaro Magna Graecia, Catanzaro, Italy; ${ }^{2}$ Laboratory of Clinical Chemistry and \\ Microbiology, IRCCS Orthopedic Institute Galeazzi, Milano, Italy; ${ }^{3}$ Department of Biomedical, Surgical and Dental Sciences, \\ Università degli Studi di Milano, Milano, Italy; ${ }^{4}$ IRCCS Orthopedic Institute Galeazzi, Milano, Italy; ${ }^{5}$ Department of Medicine \\ and Surgery, University of Milano-Bicocca, Monza, Italy; ${ }^{6}$ Department of Conservative Dentistry and Endodontics, Manipal \\ College of Dental Sciences, Manipal Academy of Higher Education, Manipal, Karnataka, India; and ${ }^{7}$ Department of Radiation \\ Biology and Toxicology, Manipal School of Life Sciences, Manipal Academy of Higher Education, Manipal, Karnataka, India
}

\section{Abstract}

Giardino L, Bidossi A, Del Fabbro M, Savadori P, Maddalone M, Ferrari L, Ballal NV, Das S, Rao BSS. Antimicrobial activity, toxicity and accumulated hard-tissue debris (AHTD) removal efficacy of several chelating agents. International Endodontic Journal.

Aim To evaluate the antimicrobial, toxicity and cleaning effectiveness of ethylenediaminetetraacetic acid (EDTA) and maleic acid (MA) alone and combined with cetrimide (CTR).

Methodology Cytotoxic and genotoxic effects were assessed on Chinese hamster cells V79 using the MTT, clonogenic and micronucleus assays, respectively. The bacterial inhibitory and bactericidal concentrations (MIC and MBC, respectively) were determined on a strain of Enterococcus faecalis. Antimicrobial tests were performed on a biofilm model after treatment with the chelating agents by using a biofilm eradication concentration (MBEC) and confocal laser scanning microscope (CLSM) assays. Quantification of cell biomass and percentage of live and dead cells in the biomass were assessed for each group. The percentage reduction of accumulated hard-tissue debris (AHTD) after root canal preparation and final irrigation protocols was evaluated by micro-CT. Statistical tests of one-way analysis of variance (ANOVA), Bonferroni test, Kruskal-Wallis test, Dunn's multiple comparison test and Wilcoxon matched-pairs signedrank tests were used.

Results Cetrimide alone as well as in combination with EDTA and MA at dilutions of $1 / 10$ and $1 / 100$ was significantly more toxic as compared to untreated controls $(P<0.001)$. All tested mixtures were nontoxic at a dilution of $1 / 1000$. EDTA retained a weak inhibitory and bactericidal effect against planktonic cells, whilst MA inhibited cells growth and killed 99.9\% of the cells when diluted. CTR revealed the most prominent effect, being inhibitory and bactericidal, also when diluted. Cetrimide alone or combined with EDTA was able to remove, respectively, $40 \%$ $(P<0.01)$ and $60 \%(P<0.001)$ of the entire biomass after $1 \mathrm{~min}$. Conversely, MA alone and in combination with CTR did not have a significant effect on biomass reduction. After final irrigation, the AHTD volume was significantly decreased in all groups $(P<0.05)$. EDTA + CTR and MA + CTR were associated with a significant reduction in the percentage of AHTD on the entire root canal compared to the same solutions without surfactant.

Conclusions 7\% MA was less cytotoxic in comparison with $17 \%$ EDTA. The addition of cetrimide to EDTA and MA removed accumulated hard-tissue debris effectively from the canal walls and increased their antimicrobial activity when compared to the same solutions without detergents. 
Keywords: biofilm, chelating agents, confocal laser scanning microscopy, irrigation, Micro-CT.

\section{Introduction}

The main goal of root canal treatment is to optimize root canal disinfection and to prevent re-infection of the root canal space after treatment (Zehnder 2006). Cleaning and shaping of the root canal system are considered the key requirements in eliminating microorganisms. Mechanical instrumentation of the root canal system produces an irregular, granular layer covering the canal walls known as the smear layer (McComb \& Smith 1975), which consists of inorganic dentine debris, pulp tissues, severed odontoblastic processes, necrotic debris, microorganisms and their metabolic products (Torabinejad et al. 2002). Studies have demonstrated that removal of smear layer improves the fluid-tight seal of filled root canals, allows the elimination of bacteria within the dentinal tubules and facilitates the penetration of intracanal medicaments, irrigating agents and sealers into the dentinal tubules, increases the bond strength of resin sealers to root canal dentine, resulting in a significantly better apical seal (White et al. 1984, Cergneux et al. 1987, Ørstavik \& Haaapasalo 1990, Gettleman et al. 1991, Shahravan et al. 2007).

Currently, there is no single irrigating solution capable of killing bacteria, dissolving organic tissue and removing the smear layer simultaneously (Giardino et al. 2018). Hence, various studies have suggested the use of a combination of irrigants (O'Connell et al. 2000, Teixeira et al. 2005). Combined application of ethylenediaminetetraacetic acid (EDTA) and sodium hypochlorite $(\mathrm{NaOCl})$ is frequently recommended for effective removal of the smear layer from the root canal system (Zehnder et al. 2005). Also, irrigating agents intended for endodontic use should be biocompatible when applied as intended (Peters 2013).

Conflicting results on the biofilm disruption or antimicrobial effects of EDTA have been demonstrated (Heling et al. 1999, Arias-Moliz et al. 2008, Ballal et al. 2011, Ordinola-Zapata et al. 2012). The only antibacterial property associated with EDTA is to weaken the bacterial cell membrane without killing the cell and thus promoting biofilm detachment (de Almeida et al. 2016). EDTA per se is not an effective antimicrobial agent (Reidmiller et al. 2006). However, since it disperses biofilms (Cavaliere et al. 2014) and permeabilizes cell membranes (Chávez de Paz et al. 2010), it could aid in sensitizing biofilms to antimicrobials.

Regarding its biocompatibility, it has been shown that extrusion of even a low concentration of EDTA solution through the apical constriction cannot only lead to an irreversible decalcification of the periapical bone but can also have consequences for neuroimmunological regulatory mechanisms (inflammatory reactions and immune response) involved in periapical lesion even in lower concentrations than those used in Endodontics (Segura et al. 1996). Also, many studies conducted using cytotoxicity assays on cell cultures have reported the cytotoxic effects of EDTA at various concentrations (Malheiros et al. 2005, Ballal et al. 2009a). Using cell viability - MTT assay and genotoxicity, it has been reported that EDTA was the least cytotoxic of irrigation solutions, used either individually or in combination (Botton et al. 2016), which is in disagreement with previous studies mentioned above.

Maleic acid (MA) has been proposed as a chelating agent for the removal of smear layer from the root canal system. At 7\% concentration, MA was associated with better smear layer removal (especially in the apical third) and less toxicity than 17\% EDTA (Ballal et al. 2009a,b, Ballal et al. 2019a).

The high surface tension of chelating agents (Giardino et al. 2006) could represent a further drawback, because of preventing its smear layer removal ability in the less accessible areas of the root canal space. Due to these limitations, recently, new chelating solutions alone or combined with surface-active agents have been investigated (Dunavant et al. 2006, Liu et al. 2015, Ballal et al. 2018). It was reported that cetrimide (CTR) added to the EDTA decreases the surface tension of the solution (Yilmaz et al. 2011), increasing the penetration of the mixture into the dentinal tubules and even into the uninstrumented areas of the root canal system. EDTA + CTR also displayed antibacterial activity, decreasing the biofilm mechanical stability by destabilization of the cohesive forces of the biofilm (Arias-Moliz et al. 2010). Interestingly, $7 \%$ MA alone or in association with CTR also had antimicrobial activity against E. faecalis from $30 \mathrm{~s}$ of exposure onward (Ferrer-Luque et al. 2010). 
Conversely, in the study mentioned above (FerrerLuque et al. 2010), the combination of EDTA and CTR eradicated biofilm grown in the MBEC-HTP device after 1 min of contact.

In order to investigate the suitability of these recently proposed irrigants for the disinfection of the root canal system, this study aimed to evaluate the antimicrobial activity, the toxicity and cleaning effectiveness of EDTA and MA alone and in combination with a detergent (CTR).

The null hypothesis tested was that the addition of CTR to EDTA or MA does not affect their antimicrobial activity, toxicity and cleaning efficiency.

\section{Materials and Methods}

\section{Preparation of the test agents}

For this study, freshly prepared chelating solutions and the concentrations assayed were as follows:

17\% EDTA (Carlo Erba Reagents Srl, Milano, Italy) 17\% EDTA + 0.5\% CTR (Sigma-Aldrich, Milano, Italy)

7\% MA (Carlo Erba Reagents Srl, Milano, Italy)

$7 \% \mathrm{MA}+0.5 \% \mathrm{CTR}$

$0.5 \%$ CTR

The 17\% EDTA and 7\% MA solutions were prepared individually and used as such, or combined adding $0.5 \mathrm{~g}$ of CTR to $100 \mathrm{~mL}$ of each chelating solution (w/v \%), and adjusted to $\mathrm{pH} 7.5$ and 3.3, respectively. The solution of $0.5 \%$ CTR was obtained by adding $0.5 \mathrm{~g}$ of detergent to $100 \mathrm{~mL}$ of deionized water.

\section{Cytotoxicity and genotoxicity assessment}

Cell culture and maintenance

Chinese hamster lung fibroblast (V79) cells were procured from NCCS, Pune, India, and maintained as per ATCC guidelines. The cells were cultured in Dulbecco's Modified Eagle Medium (DMEM; AT151, Himedia Laboratories, Mumbai, India) supplemented with $10 \%$ foetal bovine serum (RM9955, Himedia Laboratories) and $1 \times$ antibiotic antimycotic mix (A002, Himedia Laboratories) and maintained at 37 ${ }^{\circ} \mathrm{C}$ in a 5\% CO2 incubator (Galaxy 170S, Eppendorf, Hamburg, Germany).

Preparation of test solutions and MTT assay

The test solutions were freshly diluted in DMEM on the day of experimentation. The effects of various dilutions of the drugs, namely $1 / 10 ; 1 / 50 ; 1 / 100 ; 1 / 500$; and $1 / 1000$, were tested for its effect on cell viability by MTT assay as described previously (Mosmann 1983). Briefly, $10^{4}$ cells per $100 \mu \mathrm{L}$ were seeded in 96-well cell culture grade plates and allowed to attach overnight in a $5 \% \mathrm{CO}_{2}$ incubator maintained at $37^{\circ} \mathrm{C}$. The next day, the cells were treated with various dilutions of the drugs for $15 \mathrm{~min}$ that were prepared in pre-warmed DMEM. After $15 \mathrm{~min}$ of incubation with the drugs, cells were incubated with $1 \mathrm{mg} \mathrm{mL}^{-1}$ MTT reagent prepared in DMEM devoid of phenol red and serum. Cells were incubated with MTT reagent for four hours following which the formazan crystals was dissolved by adding $100 \mu \mathrm{L}$ of DMSO. The optical density (OD) of each well was obtained at $570 \mathrm{~nm}$ using a multi-well plate reader. Cell viability was determined by the following formula:

$$
\begin{aligned}
& \% \text { Viability }=\left[\begin{array}{c}
(\text { test OD }- \text { blank OD }) / \\
(\text { control OD }- \text { blank OD })
\end{array}\right] \times \\
& 100 \text { where, control corresponds to untreated cells }
\end{aligned}
$$

\section{Clonogenic assay}

This assay was carried out using the original method of Puck \& Marcus (1955). A known number of cells were seeded on 6-cm petri-dish and cultured overnight for attachment. Six hundred cells were seeded for treatment groups receiving 1:10 and 1:100 dilutions of the drugs, whereas 200 cells were seeded for control cell and 1:1000 dilutions. Next, cells were treated with the mentioned dilutions of the test agents and incubated at $37^{\circ} \mathrm{C}$ for $15 \mathrm{~min}$. After treatment, the drug-containing DMEM was removed, and the cultures were further incubated at $37^{\circ} \mathrm{C}$ for 12 days in DMEM to allow colony formation. Fixing and staining of the colonies were done using $0.1 \%$ crystal violet dissolved in methanol. Stained colonies were counted manually, and the surviving fraction in each treatment group was determined by the expression given below.

Plating efficiency; $\mathrm{PE}=$ (number of colonies counted/number of cells seeded) $\times 100$ where $\mathrm{PE}$ is calculated using the number of colonies obtained in the untreated or control cells.

Surviving fraction; $\mathrm{SF}=\{[$ number of colonies counted]/[number of cells seeded $\times(\mathrm{PE} / 100)]\}$.

Assessment of genotoxicity using a micronucleus assay Evaluation of genotoxicity was carried out by employing an in vitro micronucleus assay. For this, $6 \times 10^{5}$ cells were seeded on 6-cm culture dishes and allowed 
to attach overnight. On the following day, cells were treated with the various test solutions (1:1000 dilution in DMEM) for $15 \mathrm{~min}$. Next, the drug-containing media was removed and cells incubated in cytochalasin B $\left(3 \mu \mathrm{g} \mathrm{mL}^{-1}\right)$ in DMEM for $24 \mathrm{~h}$ and further processed as described earlier (Ballal et al. 2019b). Briefly, after treatment, the cells were harvested, submitted to hypotonic shock in $0.075 \mathrm{M} \mathrm{KCl}$ and were fixed with ice-cold fixing solution (containing 3:1 methanol:glacial acetic acid). Fixed cells were smeared on clean glass slides and stained with acridine orange dye. For analysis, 1000 binucleated cells were scored under a fluorescence microscope (BX51, Olympus, Japan) for the presence of micronuclei.

\section{Assessment of antimicrobial activity}

Bacterial strains and culture media

Enterococcus faecalis (E. faecalis) strain ATCC 4083, stored at $-80^{\circ} \mathrm{C}$ before analysis, was used because it was primarily isolated from the root canal of a pulpless tooth (Stuart et al. 2006). Then, before use, the strain was thawed and reconstituted in Tryptic Soy Agar (TSA; Biomérieux, Marci l'Etoile, France) for $24 \mathrm{~h}$ at $37^{\circ} \mathrm{C}$.

Determination of minimum inhibitory concentration (MIC) and Minimum bactericidal concentration (MBC)

Minimum inhibitory concentration (MIC) and minimum bactericidal concentration (MBC) of the chelating agents under investigation were determined by the broth microdilution method, following the guidelines of the European Committee on Antimicrobial Susceptibility Testing (http://www.eucast.org/fileadmin/ src/media/PDFs/EUCAST_files/MIC_testing/Edis5.1_b roth_dilution.pdf). A microbial suspension at an optical density equal to $0.5 \mathrm{McF}$ arland standard in Muller Hinton broth (MHB; Biolife Italiana S.r.l. Milano, Italy) was prepared from E. faecalis ATCC 4083. After obtaining a microbial load of $5 \times 10^{6} \mathrm{CFU} \mathrm{mL}^{-1}$ using appropriate dilutions, $10 \mu \mathrm{L}$ of each suspension was inoculated in a 96-well microplate containing $90 \mu \mathrm{L}$ of a serial twofold dilution of the chelating solutions (17\% EDTA, 17\% EDTA + 0.5 CTR, 7\% MA, 7\% MA + 0.5 CTR, 0.5 CTR). Bacterial growth in the control group was performed by inoculating the E. faecalis suspension in MHB. MIC values were read after $24 \mathrm{~h}$ of incubation at $37^{\circ} \mathrm{C}$. The $\mathrm{MBC}$, defined as the lowest concentration of an antimicrobial substance able to kill $99.9 \%$ of the initial inoculum, was determined by subculturing $10 \mu \mathrm{L}$ of microbial suspension from wells showing no visible growth in the MIC tests. Similarly, MBC values were read after $24 \mathrm{~h}$ of incubation at $37^{\circ} \mathrm{C}$.

Determination of Minimum biofilm eradication

concentrations (MBEC)

For biofilm susceptibility to chelating agents, the MBEC $^{\mathrm{TM}}$ High-throughput (HTP) assay (Innovotech, Edmonton, Alberta, Canada) was used. The wells were filled with $150 \mu \mathrm{L}$ of Brain Heart Infusion (BHI) broth (Biolife Italiana S.r.l. Milano, Italy) inoculated with $10^{7} \mathrm{CFU} \mathrm{mL} \mathrm{m}^{-1}$ of E. faecalis resuspended from an overnight culture on Tryptic Soy Agar (TSA Biolife Italiana S.r.l.) and incubated for $24 \mathrm{~h}$ at $37^{\circ} \mathrm{C}$ to establish a biofilm on the pegs located on the lid of the device. After the incubation, the lid was placed for approximately $30 \mathrm{~s}$ in a sterile 96-well microplate containing $200 \mu \mathrm{L}$ of sterile saline solution (rinse plate) to remove unattached cells. Afterwards, the lid was placed on a 'challenge plate' containing $200 \mu \mathrm{L}$ of a serial twofold dilution of the five chelating solutions for 1 and $5 \mathrm{~min}$ whilst agitating on an orbital shaker and moved again in a new rinse plate for 30' to neutralize the test solutions.

Then, the lid was placed in a new 96-well microplate containing $200 \mu \mathrm{L}$ of $\mathrm{BHI}$ broth and placed in a dry stainless steel tray sitting in a water bath and sonicated at maximum power for 10' to dislodge the remaining biofilm on the pegs. The lid was then removed, replaced with a nonpegged lid, and the plate incubated overnight at $37^{\circ} \mathrm{C}$. MBEC values were determined by visually checking the wells for turbidity. Clear wells indicated complete biofilm eradication.

For viable cell counting, three pegs were removed from the $\mathrm{MBEC}^{\mathrm{TM}}$ - HTP lid biofilm treated devices to both established periods, washed three times with sterile saline solution to remove unattached bacteria then placed in sterile microtubes and sonicated (VWR International, Radnor, PA, USA) at maximum power for $10 \mathrm{~min}$. Supplemental pegs treated with sterile saline solution serve as positive controls. The resulting suspensions were serially diluted, and $10 \mu \mathrm{L}$ of each dilution was seeded in TSA plates and grown overnight at $37^{\circ} \mathrm{C}$ for colony counting.

Confocal Laser Scanning Microscopy (CLSM) analysis Enterococcus faecalis biofilm was cultured on uncoated 10-mm diameter glass slides (VWR International Srl, Milano, Italy) placed in 24-well microplates for $48 \mathrm{~h}$, by inoculating bacterial cells in $1 \mathrm{~mL}$ of $\mathrm{BHI}$ broth to a final concentration of $10^{7} \mathrm{CFU} \mathrm{mL} \mathrm{m}^{-1}$. At the end of 
the incubation time, the culture medium was removed, and two washes with sterile saline were performed to remove nonadherent bacteria. Afterwards, the biofilm was treated with each of the testing solutions for 1 and $5 \mathrm{~min}$ (controls were treated with sterile saline); then, the solutions were removed, and the wells were washed twice with saline.

Glass slides were then stained with Filmtracer ${ }^{\mathrm{TM}}$ LIVE/DEAD ${ }^{\mathrm{TM}}$ Biofilm Viability Kit (Thermo Fisher Diagnostics SpA, Rodano, Italy), prepared according to manufacturer instructions. Each sample was stained with $30 \mu \mathrm{L}$ of staining solution by incubating for $15 \mathrm{~min}$ at room temperature in the dark.

Later, stained biofilms were thoroughly rinsed in physiological solution and the images acquired with a Confocal Laser Scanning Microscope TCS SP8 (Leica Microsystems CMS GmbH, Mannheim, Germany) using a $20 \times$ dry objective (HC PL FLUOTAR $20 \times 1$ 0.50 DRY). Sequential optical sections were gathered along the z-axis for the entire thickness of the biofilm. Images from at least three random areas were acquired for each sample. The selected images were processed with Las X (Leica Microsystems CMS $\mathrm{GmbH}$ ) and analysed with Fiji software (Fiji; ImageJ, Wayne Rasband, NIH Bethesda, Maryland, USA). The quantification of cells biomass was expressed in $\mu \mathrm{m}^{3}$. The percentage of live and dead microorganisms in the biomass was assessed in each group.

\section{Quantification of accumulated hard-tissue debris (AHTD) using Micro-CT}

\section{Sample size calculation}

The effect size of AHTD removal for this study was $91 \%$, based on a previous study with similar methodology (Silva et al. 2019), and was combined with a power $\beta=0.95$, and $\alpha=0.05$ into an $F$-test family for one-way Anova ( $\mathrm{G}^{*}$ Power 3.1.7 software for Windows; Heinrich Heine, Universität Düsseldorf, Düsseldorf, Germany). The minimum sample size to reveal statistical significance amongst groups amounted to twenty-six samples in total. Additional samples were used, in order to compensate for possible sample loss.

\section{Root canal selection and preparation}

The experimental protocols were approved by the institutional ethics committee for the use of human extracted teeth (IEC 519/2019). A total of fifty maxillary incisors with straight roots, single relatively round canals in cross-section, were established initially using a micro-CT method (Peters et al. 2010,
Versiani et al. 2019), and similar root length was selected from a pool of extracted teeth. Each tooth was radiographed in both mesiodistal and buccolingual directions to verify the presence of a single canal with closed apex, the absence of intra-radicular resorption, presence of caries, restoration, or fractures or root canal filling. The teeth were stored in $0.2 \%$ sodium azide (Millipore Sigma, St. Louis, MO, USA) at $4^{\circ} \mathrm{C}$ until use. The teeth were decoronated at the cemento-enamel junction to obtain a standardized root length of $12 \mathrm{~mm}$. Before instrumentation, the samples were subjected to a pre-operative scanning procedure by using a micro-CT device (Skyscan 1176, Bruker, Kontich, Belgium). Each tooth was scanned separately at an isotropic resolution of $8.92 \mu \mathrm{m}$. The scanner parameters were set at $90 \mathrm{kV}, 280 \mu \mathrm{A}, 0.5^{\circ}$ rotation around the vertical axis, and rotation step of $0.4^{\circ}$, using a $0.1-\mathrm{mm}$-thick copper filter.

The volume of interest was selected extending from the cemento-enamel junction to the apex of the root, resulting in the acquisition of 671-675 transverse cross-sections per tooth. Aiming to create a similar sample amongst the groups, ten anatomically pair-matched teeth, presenting a single ovalshaped canal, were selected based on similar morphological features of the root canal such as length, volume and configuration to compose the experimental groups (De-Deus et al. 2019). The volume of the initial pre-shaping root canal for each element was calculated, and the five groups were compared to verify that the samples did not present anatomical or structural differences that could create disparities between groups. No statistically significant values between the groups, regarding the initial volume of each root canal, were found (One-way ANOvA, $P=0.46$ ); therefore, the samples were homogeneous for initial volume, then distributed amongst the five study groups and used for the shaping procedures.

The apical third of each tooth was sealed with a layer of cyanoacrylate adhesive to simulate an ex vivo closed-end model (Giardino et al. 2017). The glide path in the samples of all the groups was accomplished with a 15 K-file (Dentsply Sirona, Ballaigues, Switzerland) until the apical foramen. Working length was established by inserting a size $10 \mathrm{~K}$-file (Dentsply Sirona) into each root canal until it was just visible at the apical foramen (observed using magnifying loupes) then subtracting $1 \mathrm{~mm}$ from the recorded length. Each sample, then, was shaped mechanically to $1 \mathrm{~mm}$ before of the apical foramen (established 
working length) using the NiTi rotary system ProTaper Next (Dentsply Sirona) to a size 30, .07 taper. At each instrument changeover, the canal was irrigated with $1 \mathrm{~mL}$ of $5.25 \% \mathrm{NaOCl}$ (Ogna Laboratori Farmaceutici, Muggiò, Italy) for 1 min using a syringe with a 30-gauge side-vented needle (Max-i-Probe; Dentsply Rinn, Elgin, IL, USA) placed at $2 \mathrm{~mm}$ from the working length, for a total of $5 \mathrm{~mL}$ of $5.25 \% \mathrm{NaOCl}$. After root canal preparation and irrigation with 5.25\% $\mathrm{NaOCl}$ were accomplished, the teeth were submitted to a second scan, applying the parameter settings above mentioned.

\section{Final irrigation protocols}

After root canal preparation, each specimen was randomly assigned to one of the five experimental groups ( $n=10)$, according to the final irrigation protocol:

Group $1-5.25 \% \mathrm{NaOCl}$ followed by saline

Group $2-5.25 \% \mathrm{NaOCl}$ followed by $7 \% \mathrm{MA}$

Group $3-5.25 \% \mathrm{NaOCl}$ followed by $7 \%$

$\mathrm{MA}+0.5 \% \mathrm{CTR}$

Group $4-5.25 \% \mathrm{NaOCl}$ followed by $17 \%$ EDTA

Group $5-5.25 \%$ NaOCl followed by $17 \%$

EDTA + 0.5\% CTR

For final irrigation, in all the groups, each specimen was irrigated with $2 \mathrm{~mL}$ of test agents assigned for $2 \mathrm{~min}$. To remove chemical residues, the canals were flushed with $5 \mathrm{~mL}$ of distilled water and dried with size 30 absorbent paper points (Dentsply Sirona).

Then, a third scan was performed in all samples included in the five groups listed above after final irrigation with the assigned chelating agent to quantify the accumulation of hard-tissue debris. The images were reconstructed using a scanner software (NRecon 1.6.10.4; Skyscan, Bruker, Kontich, Belgium) with a beam hardening correction of $40 \%$ and ring artefact correction of 10 .

To ensure that the three scans performed for each element could be analysed with the same references, the Data Viewer software (Data Viewer v.1.5.1, Bruker) was used.

The segmentation threshold to separate dentine and debris from the root canal space and the quantitative analyses were then performed by using CTAn software (CTAn v.1.14.4, Bruker) to calculate quantitative parameters and CTVol (CTVol v.2.2.3.0, Bruker) to reconstruct visual 3D models. By using CTAn software, it was also possible to obtain the volumetric values of the debris present in the root canal by calculating in percentage the reduction of debris before and after the final irrigation in each group.
The total volume of AHTD was calculated in cubic millimetre $\left(\mathrm{mm}^{3}\right)$ and expressed as the percentage of the entire canal system volume after preparation (vol \%).

\section{Statistical analysis}

The normality of data distributions was assessed using the D'Agostino \& Pearson's test and the Shapiro-Wilk test. For data distributed normally, results were presented as means and standard deviations (SD), and one-way analysis of variance (ANOvA) was used together with the post hoc Tukey multiple comparison test for between-group comparisons. For toxicity assays, between-group comparisons were made using a one-way ANOva followed by Bonferroni's correction. For assessing differences in root canal volume before and after preparation, and in AHTD removal, withingroup comparisons were performed using the paired Student t-test. For data not following a normal distribution, amongst-group comparisons were assessed by using the Kruskal-Wallis test and the Dunn's multiple comparison test, and the Wilcoxon matched-pairs signed-rank test was used for within-group comparisons. Statistical analysis was undertaken using the software GraphPad Prism 5.0 (GraphPad Software, La Jolla, CA, USA). The significance threshold was set at $P=0.05$.

\section{Results}

\section{Toxicity assessment}

Changes in the cell viability in V79 cells in the presence of different dilutions of the test compounds were determined by MTT Assay. The viability of cells in the presence of the test compounds is shown in Figure 1. A group-wise statistical comparison for the effect of different dilutions of the drugs on cell viability is shown in Table 1. Cells treated with each of the test agents at a dilution of 1:10 exhibited profound toxicity showing the lowest viability when compared to the other dilutions. Apart from EDTA, cells receiving the test agents at a dilution of 1:50 also reduced cell viability. On the other hand, cells had a gradual increase in viability with increasing dilutions of the test compounds with 1:100, 1:500 and 1:1000 dilutions. Treated cells had a significant $(P<0.001)$ increase in cell viability when compared to the group of cells receiving 1:10 dilution of each of the test agents (Fig. 1). 
The PE of the V79 cells in the present study was found to be $92.7 \pm 3.51$. The SF of V79 cells upon treatment with the various test solutions is summarized in Table 2. Representative crystal violet-stained colonies are shown in Figure 2. CTR alone, as well as in combination with EDTA and MA at dilutions of $1 /$ 10 and $1 / 100$, was significantly toxic $(P<0.001$ when compared to controls), as these did not allow colony formation. Similarly, EDTA and MA at dilution $1 / 10$, too, resulted in a significant decrease in SF (Table 2). All tested mixtures were nontoxic and showed no significant difference at a dilution of 1/1000 (Table 2).

The genotoxic potential of CTR, EDTA, MA alone, or in combination, was assessed by micronucleus assay. A 1/1000 dilution (dose selected based on viability studies) of each of the test agents was investigated for their genotoxic potential. Data indicated that the test agents did not exhibit a significant increase in micronucleus frequency as compared to control cells showing their nongenotoxic nature at this tested dilution (Fig. 3).

\section{Antimicrobial activity}

Employing the broth microdilution method (MIC and MBC), EDTA retained a weak inhibitory and bactericidal effect against planktonic cells, whilst MA inhibited cells growth even when diluted 1:16 and killed 99.9\% of the cells when diluted 1:8 (Table 3). CTR revealed the most prominent effect, being inhibitory, also when diluted 1:1024 and bactericidal at 1:512. Whilst the addition of EDTA did not improve neither MIC nor MBC values of CTR, the addition of MA improved its bactericidal activity of one dilution (Table 3). When MBEC assay was employed to assess the biofilm removal activity of the surfactant agents, CTR was once again the most active agent, being able to remove completely E. faecalis biofilm from the MBEC pegs diluted 1:8 and 1:32, respectively, when applied for 1' and 5' (Table 3). Only the addition of EDTA slightly improved CTR removal activity (Fig. 4, 5).

To assess the irrigating solutions ability to eradicate enterococcal sessile cells encased in an exopolymeric matrix, mature biofilm was challenged for 1 and 5 min and analysed using CLSM.

Compared to the control, a significant biomass reduction was observed when EDTA was present in the solution. CTR alone was able to remove 30-40\% of the whole biomass and when added to EDTA, was not able to improve the removal of the sessile cells. However, the percentage of dead cells significantly increased when CTR was added to the irrigant solutions (Fig. 4, 6). Conversely, MA displayed a lower bactericidal activity on biofilm cells (Fig. 4) and was the only molecule that had a time-dependent activity, both when used alone or in combination.

\section{Accumulated hard-tissue debris estimation}

By using micro-CT, it was possible to identify and measure AHTD after preparation and final irrigation

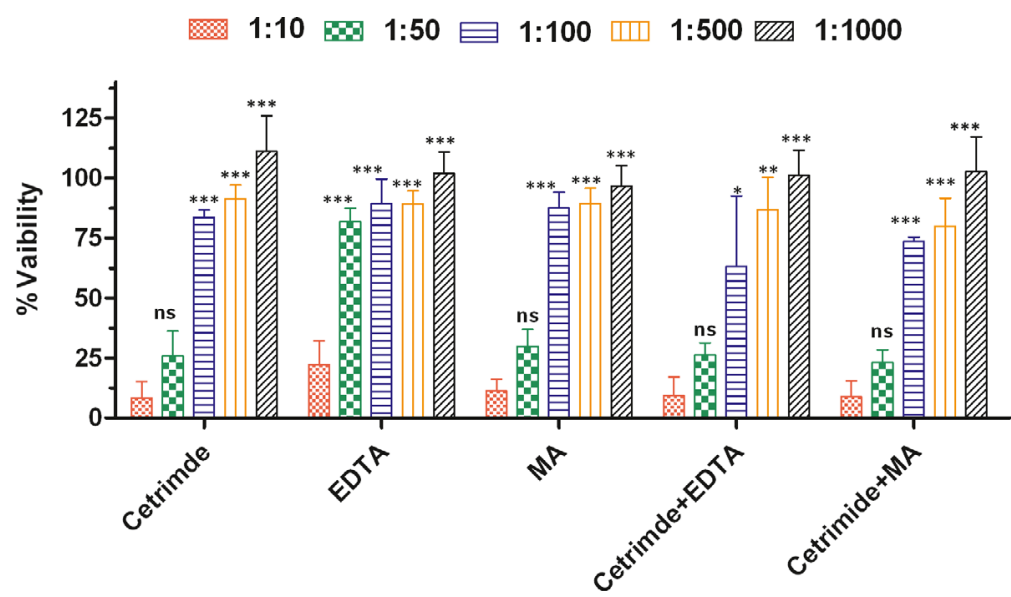

Figure 1 Graph showing changes in the viability of V79 cells in the presence of different dilutions of test agents. ns $=$ Not significant; ${ }^{*} P<0.05,{ }^{* *} P<0.01,{ }^{* * *} P<0.001$ when compared to its respective $1: 10$ dilution for each of the test compound. Control $=$ cells with DMEM alone. Data are shown as Mean \pm SD, obtained from three independent experiments. Statistical analysis was achieved using one-way ANova followed by Bonferroni's multiple comparison test. 


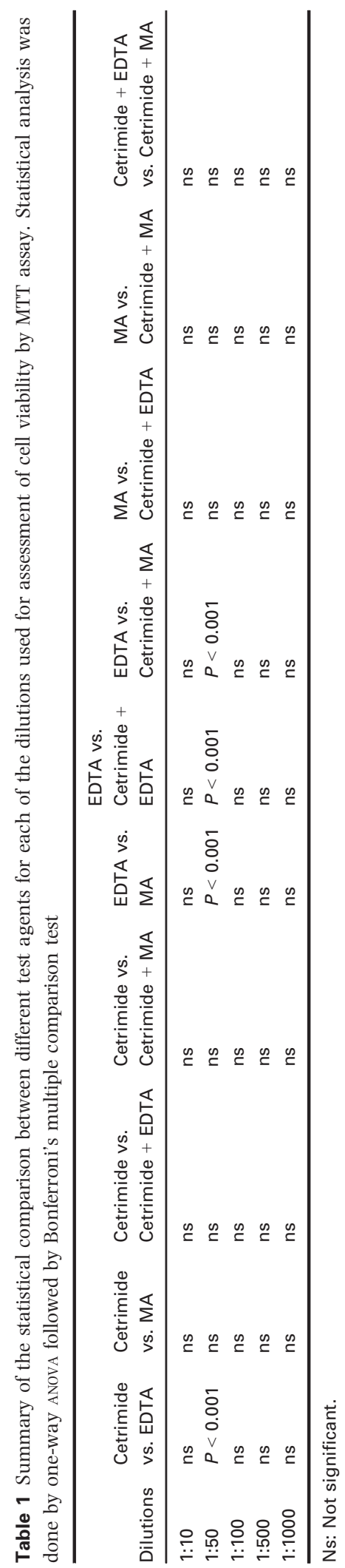

Table 2 Surviving Fraction (SF) of V79 cells treated with the different test agents

\begin{tabular}{llll}
\hline Solutions & $1: 10$ & $1: 100$ & $1: 1000$ \\
\hline Control & $1.0 \pm 0.00$ & $1.0 \pm 0.00$ & $1.0 \pm 0.00$ \\
Cetrimide & $0.00 \pm 0.00^{\mathrm{a}}$ & $0.00 \pm 0.00^{\mathrm{a}}$ & $0.86 \pm 0.15^{\mathrm{b}}$ \\
EDTA & $0.18 \pm 0.22^{\mathrm{a}}$ & $0.50 \pm 0.20^{\mathrm{a}, \mathrm{b}}$ & $0.90 \pm 0.07^{\mathrm{b}}$ \\
MA & $0.03 \pm 0.03^{\mathrm{a}}$ & $0.50 \pm 0.20^{\mathrm{a}, \mathrm{b}}$ & $1.04 \pm 0.06^{\mathrm{b}}$ \\
Cetrimide + EDTA & $0.00 \pm 0.00^{\mathrm{a}}$ & $0.00 \pm 0.00^{\mathrm{a}}$ & $0.97 \pm 0.06^{\mathrm{b}}$ \\
Cetrimide + MA & $0.00 \pm 0.00^{\mathrm{a}}$ & $0.00 \pm 0.00^{\mathrm{a}}$ & $0.96 \pm 0.03^{\mathrm{b}}$
\end{tabular}

a $P<0.001$ indicated the statistical comparison between untreated/control cells with various test agents.

${ }^{\mathrm{b}} P<0.001$ indicates the statistical comparison between the various dilutions of each test agent $(n=6)$. Statistical analysis was achieved using one-way ANOVA followed by Bonferroni's multiple comparison test.

in the root canals for all the tested protocols. The data were distributed normally. Table 4 summarizes the mean values and standard deviations for the main parameters assessed. There was no significant difference amongst groups both for pre-operative root canal volume $(P=0.46)$ and for volume after root canal preparation $(P=0.41)$. The root canal volume was significantly increased in all groups after preparation $(P<0.01)$. After preparation, there was no significant difference amongst groups for AHTD volume $(P=0.13)$. After final irrigation, the AHTD volume was significantly decreased in all groups $(P<0.01)$. The results were confirmed also expressing the AHTD data as $\%$ of the total root canal volume (Table 4). Figure 7 shows the micro-CT images of the removal of accumulated hard-tissue debris in the experimental groups, considering the whole canal.

The mean percentage of hard-tissue debris removed by the different experimental solutions is shown in Table 4. All the irrigating solutions were significantly superior to saline (control) in the overall removal of AHTD. Significant differences between groups for AHTD removal, and $P$-values of the amongst-group (ANOVA) and between-group comparisons (unpaired Student's t-test) are listed in Table 5.

\section{Discussion}

The present study investigated the toxicity, antimicrobial activity and AHTD removal of EDTA and MA alone or in combination with CTR. Since the results of this study revealed that the addition of CTR to EDTA or MA improved its antimicrobial activity and 

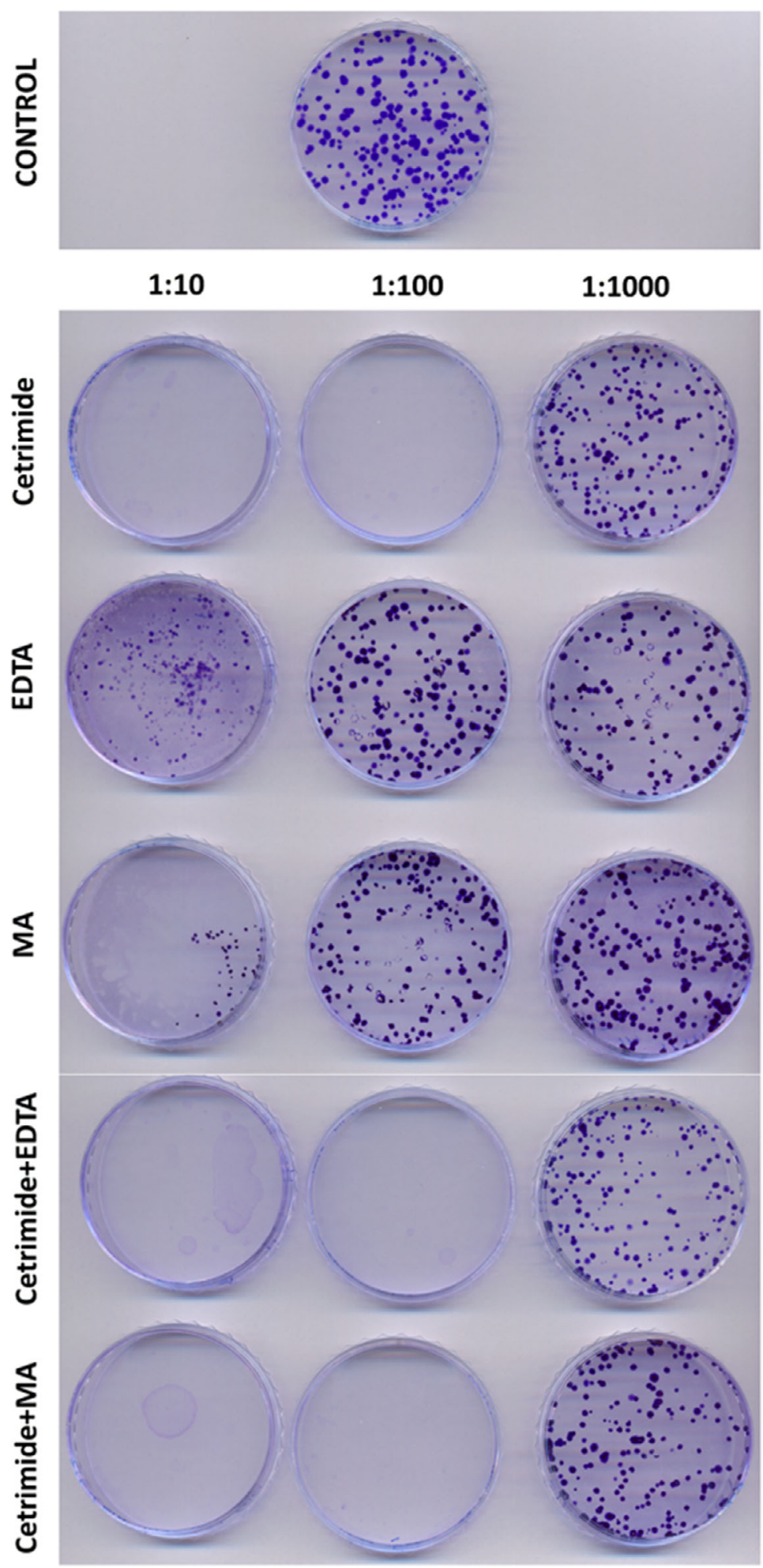

Figure 2 Representative photomicrograph showing the clonogenicity of V79 cells in the presence of different dilutions of the indicated test agents. 

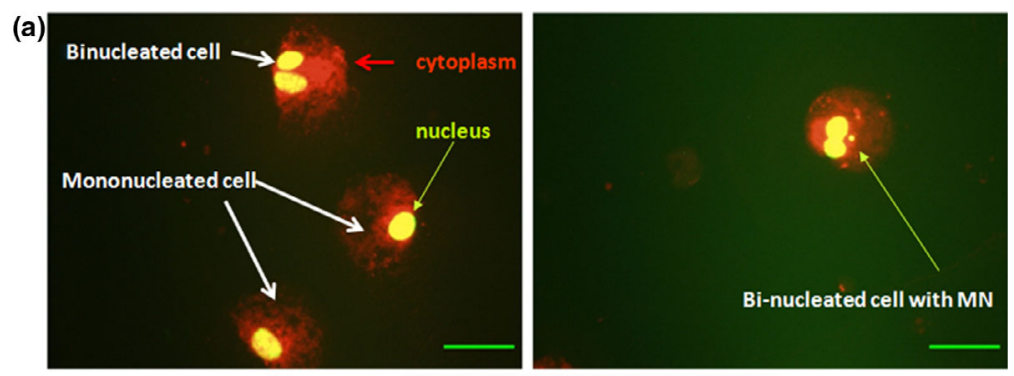

(b)

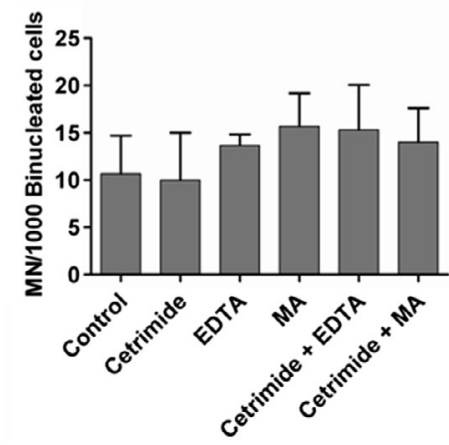

Figure 3 Representative photomicrograph of V79 cells stained with acridine orange exhibiting mononucleated and binucleated states with micronucleus. (a) Images were taken using $200 \times$ magnification using fluorescence filters with FITC-TRITC dualband fluorescence filter. Scale $=80 \mu \mathrm{m}$. (b) Graph showing the effect of different drugs tested at a dilution of 1/1000 for the induction of micronuclei (MN) in V79 cells. No symbol indicated that the changes in the MN frequency were not significant when compared to control as well as between the groups.

also AHTD removal efficiency, the null hypothesis has to be rejected.

Cytotoxicity is one of the most important factors for assessing any adverse effect of the anti-biofilm molecules before using them commercially for the prevention and removal of biofilm (Roy et al. 2018). The present work investigated various agents, namely CTR, EDTA and MA alone, and CTR in combination with EDTA and MA, for their cytotoxic potential. Viability analysis using MTT assay showed that cells treated with the test agents alone or in combination at dilution 1/10 had the highest cell killing rate. This could be attributed to their chemical property. CTR being a surfactant would readily disrupt cell membrane lipids resulting in the lysis of cells. EDTA is a strong metal chelator and can readily remove essential divalent metal ions such as $\mathrm{Ca}^{2+}$ and $\mathrm{Mg}^{2+}$, causing detachment of cells, and resulting in MTT reduction. The acidic nature of MA would contribute in a major way to killing cells at the 1/10 dilution. With an increase in dilution of each of the test agents, their toxic effect on cell viability, as shown by MTT assay, vanished.
The colony-forming assay is a gold standard assay (Franken et al. 2006) that has found profound use in estimating the cytotoxicity of agents as it measures the reproductive capacity of cells after they have undergone cellular insult. In the present investigation, V79 cells were tested for clonogenicity after treatment with the test agents. Interestingly, CTR alone and in combination with EDTA and MA at dilutions $1 / 10$ and $1 / 100$ did not allow colony formation. Although the MTT data indicated the viability of greater than $60 \%$ for CTR alone and in combination with EDTA and MA, the lack of colonies indicates their long-term impact on cell reproducibility. EDTA and MA treatment also reduced the clonal survival of V79 cells at $1 / 10$ and 1/100 dilutions but was less severe when compared to CTR and its combination with EDTA and MA. All the test agents at dilution 1/1000 were associated with colony formation similar to that of untreated/ control cells, indicating their nontoxic nature at this particular dilution.

The formation of micronuclei is an indicator of DNA damage, and this is a sensitive method to 


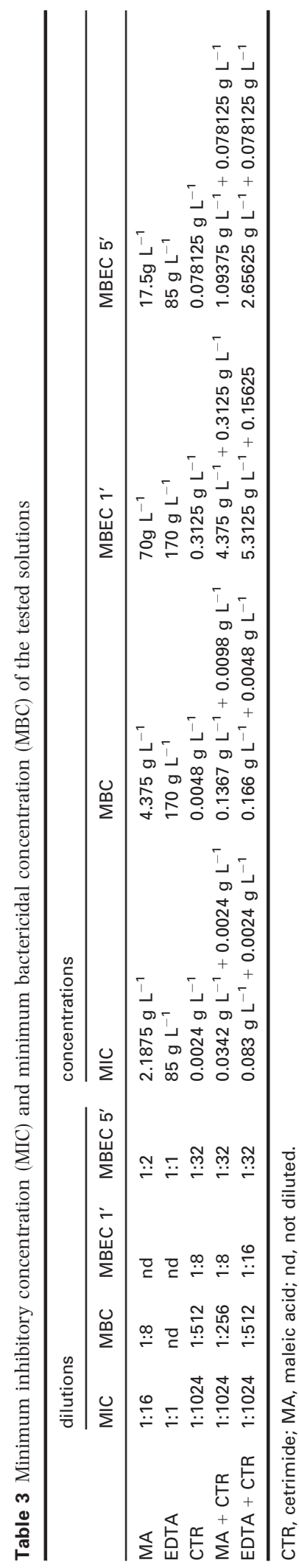

analyse the genotoxicity potential of any chemical agent (Nersesyan et al. 2016). Concerning to genotoxicity, the drugs did not induce a significant rise in the frequency of micronuclei formation in V79 cells, indicating its nongenotoxic nature at this tested concentration.

However, the assays used have several limitations when compared to in vivo conditions. Cell cultures are generally more sensitive to the toxic effects of materials than 'in vivo' tissues (Bajrami et al. 2014); under in vivo conditions, substances are diluted with body fluids and their concentration decreases (Labban et al. 2014); they are carried away from the lymph, blood and phagocytes of the vascular and lymphatic systems (Ballal et al. 2009a); in equal concentrations, the cytotoxicity of materials decreases over time in the clinical setting compared to in vitro observation (Malheiros et al. 2005). Therefore, the present results may not be directly generalizable to the in vivo settings.

As already mentioned above, conflicting results on the biofilm disruption or antimicrobial effect of EDTA have been reported. The only antibacterial property associated with EDTA was to weaken the bacterial cell membrane without killing the cell and promoting biofilm detachment (de Almeida et al. 2016). These data were herein confirmed as EDTA was not inhibitory when diluted 1:1 and not bactericidal even when not diluted and exposed to E. faecalis cells in planktonic killing tests (MIC and $\mathrm{MBC}$ ). Also, in MBEC assay, EDTA was not able to dislodge the biofilms formed on the pegs. A significant biomass reduction was observed when mature biofilm was analysed employing CLSM, in agreement with previous reports (Cavaliere et al. 2014, de Almeida et al. 2016).

MA has recently been suggested as an alternative chelator to EDTA (Ballal et al. 2009b). The highly acidic $\mathrm{pH}$ of MA, which can alter cell membrane permeability, could explain its substantial antimicrobial properties (Ferrer-Luque et al. 2010). In the present study, it was also observed that it could inhibit cell growth even when diluted 1:16 and kill $99.9 \%$ of cells when diluted 1:8 (Table 3). Conversely, the present results revealed that MA was associated with a lower bactericidal activity on biofilm cells (Fig 4), and it was able to dislodge the biofilms formed on the pegs only undiluted to $1^{\prime}$ and diluted 1:2 to $5^{\prime}$ by using MBEC assay in both treatment time.

Various ingredients such as detergents added to irrigants reduce the surface tension (Giardino et al. 2018) and enhance the antibacterial effect of the 


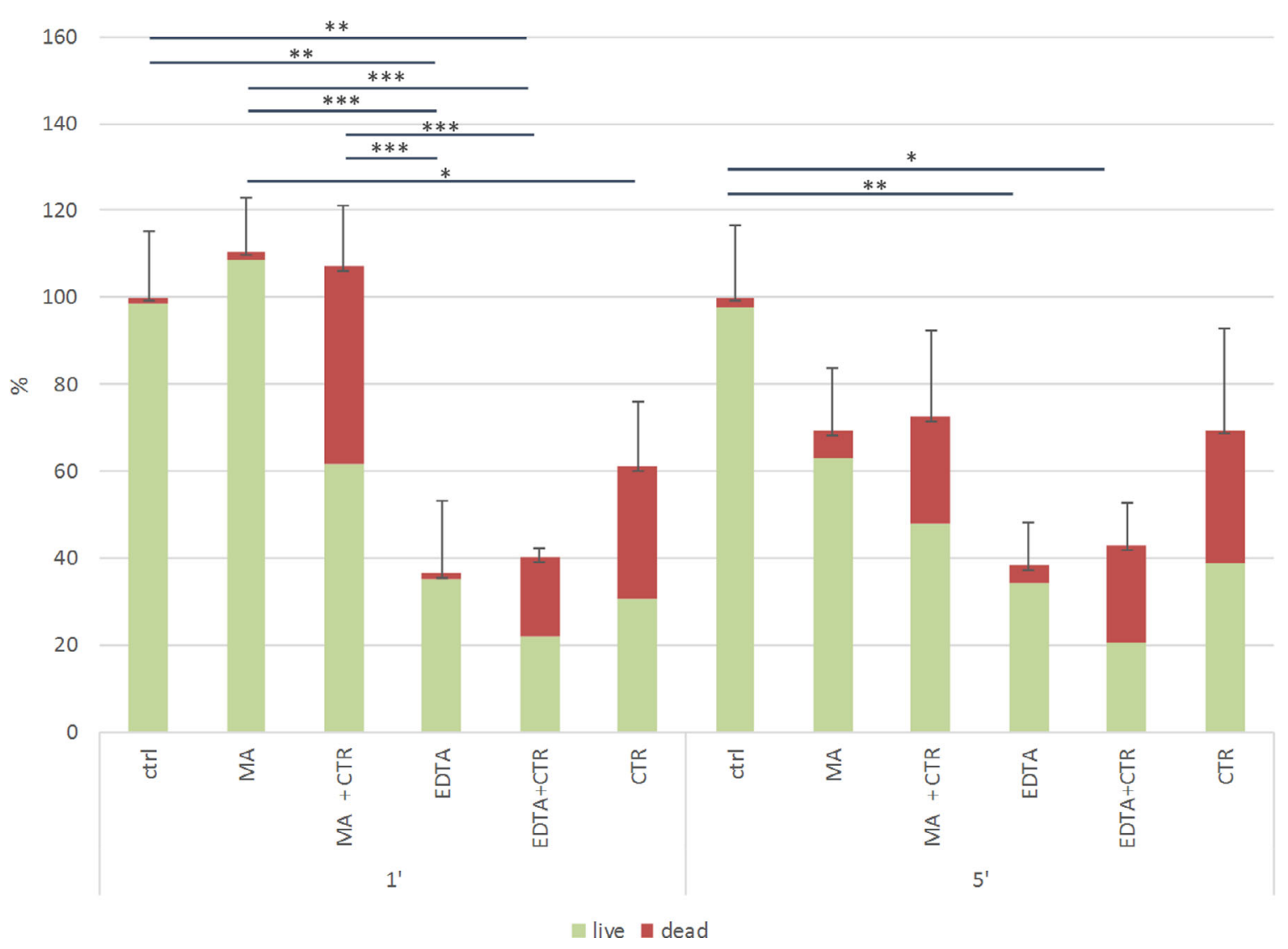

Figure 4 Biofilm removal efficacy of the tested solutions on pre-formed E. faecalis biofilm analysed by CLSM. Residual biomass is represented in percentage upon treatment with respect to the control. Whole bars represent the total biomass; the green fraction is viable cells, in red the dead cells still encased in the biofilm. Ctrl = control; MA = maleic acid; CTR $=$ cetrimide. ${ }^{*} P<0.05,{ }^{* *} P<0.01,{ }^{* * *} P<0.001$.

solutions by a residual antibacterial activity, increasing the resistance to microbial regrowth in the root canal system (Baca et al. 2012). Some studies stated that CTR, a cationic surfactant, in addition to a proven bactericidal activity and the ability to reduce the surface tension of irrigants (Wang et al. 2012), can decrease the mechanical stability of the biofilm by destabilization of the cohesive forces of the biofilm. This probably depends on the interaction between the chemical structure of the molecule and the anionic properties of the extracellular polymeric substance (EPS) surrounding the biofilm (Simões et al. 2005). All these features can contribute to greater efficiency of irrigating solutions where detergents are added, as highlighted in the current investigation, and explain the best results obtained compared to both surfactantfree solution combinations.
The results of the current study showed that CTR alone had the most prominent effect, being inhibitory also when diluted $1: 1024$ and bactericidal at 1:512. Moreover, it was able to dislodge E. faecalis biofilm completely from the MBEC pegs, respectively, when applied for 1 and 5'. This removal activity improved when mixed with EDTA.

Some researchers (De-Deus et al. 2011) formerly highlighted that scanning electron microscopic (SEM) evaluation for AHTD in a laboratory setting has a limited utility to consider a side effect of the chemomechanical preparation procedures in the intricate root canal anatomy. The status of the dentinal surface before and after the application of the chelators is unknown, so the evaluation is not performed in the very same dentine area of the same sample (De-Deus et al. 2011). 

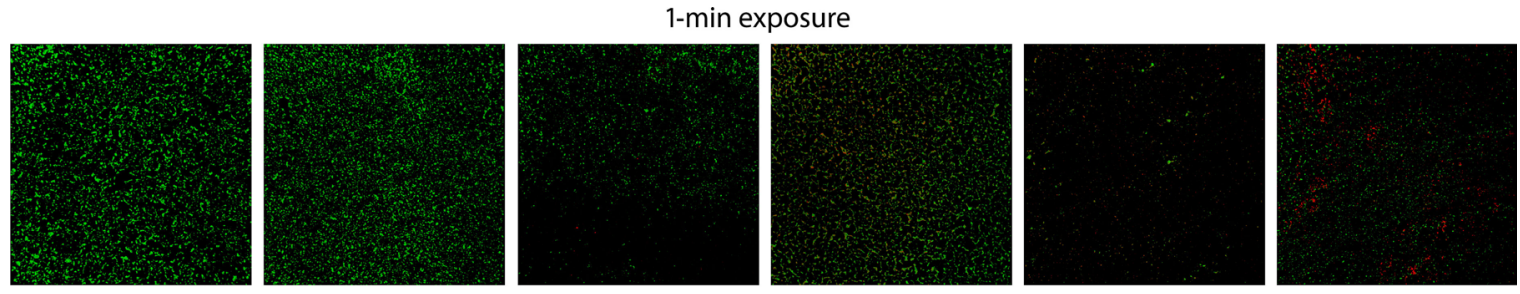

5-min exposure

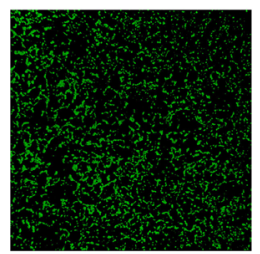

Positive control

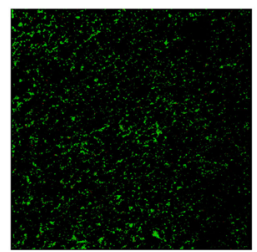

MA

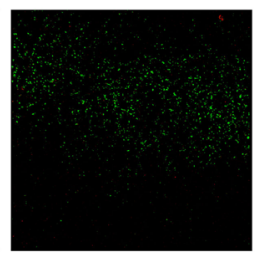

EDTA

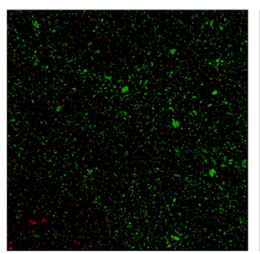

$M A+C T R$

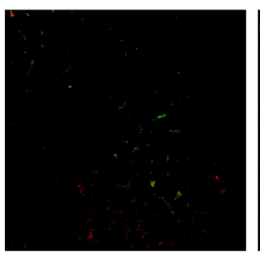

EDTA+CTR

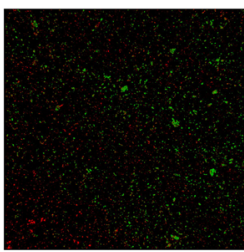

CTR

Figure 5 CLSM 3D images of E. faecalis biofilms treated with the tested solutions. MA = maleic acid; CTR = cetrimide.

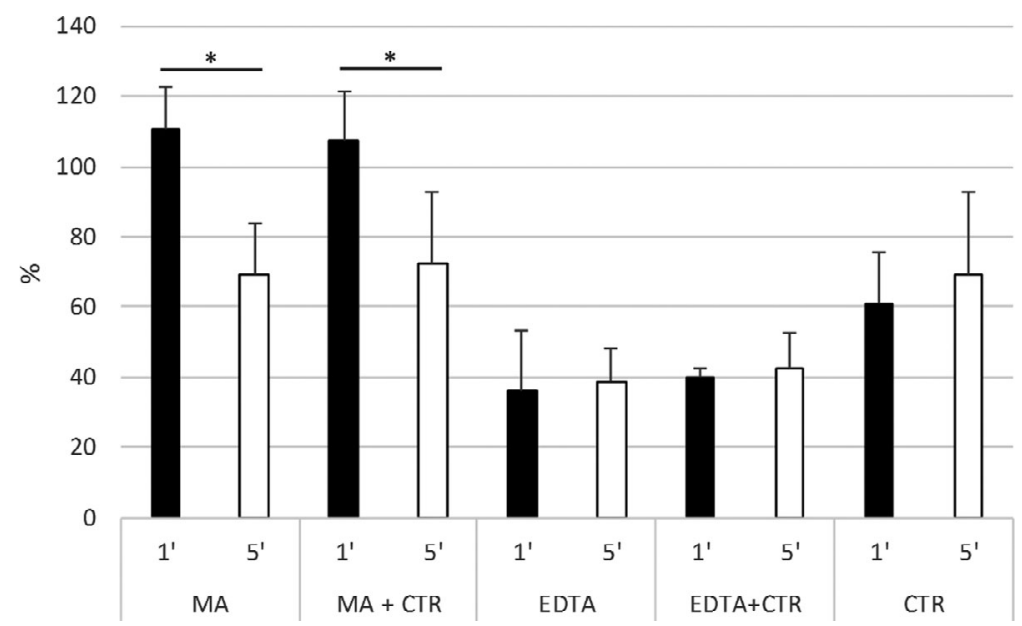

Figure 6 Exposure time effect of the tested solution on pre-formed biofilm. Black bars, 1' treatment; white bars, 5' minutes' treatment. ${ }^{*} P<0.05$.

The assessment of hard-tissue debris accumulation has been made possible through the combination of nondestructive micro-computed tomography (microCT) imaging and the development of robust image analysis and processing software (Paqué et al. 2009).

Therefore, to verify the debris removal ability of the chelators used in the present study, the 3D nondestructive micro-CT imaging was carried out because it currently represents a gold standard technique to evaluate the AHTD inside anatomical complexities of the root canal system of shaped and irrigated human teeth whilst preserving sample integrity (Keleş et al. 2016).

The present investigation showed that the percentage volume of AHTD removal after final irrigation was lower in the canals irrigated with saline solution (30.65\%) in comparison with the EDTA and MA irrigation protocols, which markedly showed less remaining debris (AHTD removal of $59.66 \%$ and $75.57 \%$ 
Table 4 Mean values and standard deviations for the main parameters assessed with micro-CT

\begin{tabular}{|c|c|c|c|c|c|c|c|c|}
\hline Parameters & & & EDTA & EDTA + Cetrimide & $\begin{array}{l}\text { Maleic } \\
\text { acid }\end{array}$ & $\begin{array}{c}\text { Maleic } \\
\text { acid }+ \text { Cetrimide }\end{array}$ & $\begin{array}{l}\text { saline } \\
\text { solution }\end{array}$ & $\begin{array}{c}P- \\
\text { value }^{\mathrm{a}}\end{array}$ \\
\hline \multirow[t]{3}{*}{$\begin{array}{l}\text { Root canal } \\
\text { space }\end{array}$} & $\begin{array}{l}\text { Volume, } \\
\mathrm{mm}^{3}\end{array}$ & $\begin{array}{l}\text { Before } \\
\text { preparation }\end{array}$ & $3.11 \pm 2.24$ & $4.25 \pm 1.33$ & $3.89 \pm 1.55$ & $3.88 \pm 0.89$ & $3.09 \pm 1.47$ & 0.46 \\
\hline & & $\begin{array}{l}\text { After } \\
\text { preparation }\end{array}$ & $5.81 \pm 1.80$ & $5.88 \pm 0.82$ & $6.11 \pm 1.47$ & $6.31 \pm 0.79$ & $5.18 \pm 0.99$ & 0.41 \\
\hline & & $P$-value ${ }^{\mathrm{b}}$ & $<0.01$ & $<0.01$ & $<0.01$ & $<0.01$ & $<0.01$ & \\
\hline \multirow[t]{3}{*}{ AHTD } & $\begin{array}{l}\text { Volume, } \\
\mathrm{mm}^{3}\end{array}$ & $\begin{array}{l}\text { After } \\
\text { preparation }\end{array}$ & $0.24 \pm 0.16$ & $0.11 \pm 0.13$ & $0.12 \pm 0.11$ & $0.29 \pm 0.22$ & $0.16 \pm 0.16$ & 0.13 \\
\hline & & $\begin{array}{l}\text { After } \\
\text { irrigation }\end{array}$ & $0.09 \pm 0.06$ & $0.02 \pm 0.03$ & $0.04 \pm 0.09$ & $0.05 \pm 0.05$ & $0.10 \pm 0.10$ & 0.52 \\
\hline & & $P$-value ${ }^{\mathrm{b}}$ & $<0.01$ & $<0.01$ & $<0.01$ & $<0.01$ & $<0.01$ & \\
\hline \multirow[t]{3}{*}{ AHTD } & $\begin{array}{c}\text { Volume, \% } \\
\text { of total }\end{array}$ & $\begin{array}{l}\text { After } \\
\text { preparation }\end{array}$ & $3.55 \pm 3.04$ & $2.23 \pm 3.05$ & $1.92 \pm 2.05$ & $3.62 \pm 3.22$ & $2.62 \pm 2.21$ & 0.53 \\
\hline & $\begin{array}{l}\text { root canal } \\
\text { volume }\end{array}$ & $\begin{array}{l}\text { After } \\
\text { irrigation }\end{array}$ & $1.30 \pm 1.29$ & $0.60 \pm 1.08$ & $0.76 \pm 1.66$ & $1.14 \pm 1.41$ & $1.54 \pm 1.59$ & 0.50 \\
\hline & & $P$-value ${ }^{b}$ & $<0.01$ & $<0.01$ & $<0.01$ & $<0.01$ & $<0.01$ & \\
\hline
\end{tabular}

AHTD = accumulated hard tissue debris.

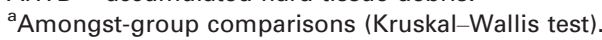

bWithin-group comparisons (Wilcoxon matched-pairs signed-rank test).

respectively), as reported in Table 5. In previous studies (Ballal et al. 2009b, Ulusoy \& Görgül 2013), MA had a better ability to remove the smear layer in comparison with EDTA. These findings were not in agreement with the present study. Currently, when MA and EDTA with or without CTR added were compared with each other, there was no significant difference between them in removal AHTD, respectively. The discrepancy with the present results might be explained by the differences in the experimental models and methods of investigation used. First, in the present study, the apical end of each sample was covered with a layer of cyanoacrylate to create a closed environment (Giardino et al. 2017) and to simulate an ex vivo closed-end model, contrary to the previous reports where the apical end of each tooth was not closed during irrigation procedures, then not reproducing the dynamics and impact on the replenishments of irrigants which does not mimic the clinical setting. As stated by Tay et al. (2010), the root is enclosed by the bone socket during in vivo irrigation; then, the root canal behaves as a closed-end channel, which results in gas entrapment at its closed-end, producing a vapour lock effect during irrigant delivery. For the closed system, the effect of a vapour lock was most conspicuous along the apical portion of the canal, with retention of debris and smear layer remnants, contrary to the open system, where complete smear layer removal and debris clearance were seen. Secondly, in the present study, a micro-CT assay was used to investigate the hard debris removal ability of the irrigants in place of SEM evaluation, a scientifically questionable tool to study the real effect of the chelating solutions because the lack of solid and reliable experimental features, where the results may not be precisely determined (De-Deus et al. 2011). In line with the present findings, it has been reported that there is no significant difference found between MA and EDTA groups in smear layer removal (Jaiswal et al. 2018). However, MA has shown better smear layer removing ability than EDTA, experimentally.

The addition of CTR to EDTA and MA produced similar outcomes in AHTD removal $(80.83 \%$ and $82.07 \%$ respectively), resulting in a significant improvement over both solutions used without detergent. This suggests that the addition of surfactant improves the properties of the chelators, in line with the existing literature, which recommends the use of chelators enriched with surfactants (Yilmaz et al. 2011, Ballal et al. 2018). These results reconfirm the correlation between wettability of irrigants and effectiveness in removing debris since a greater diffusion is obtained both inside the canal and in its ramifications, and microscopically at the level of the dentinal tubules. 


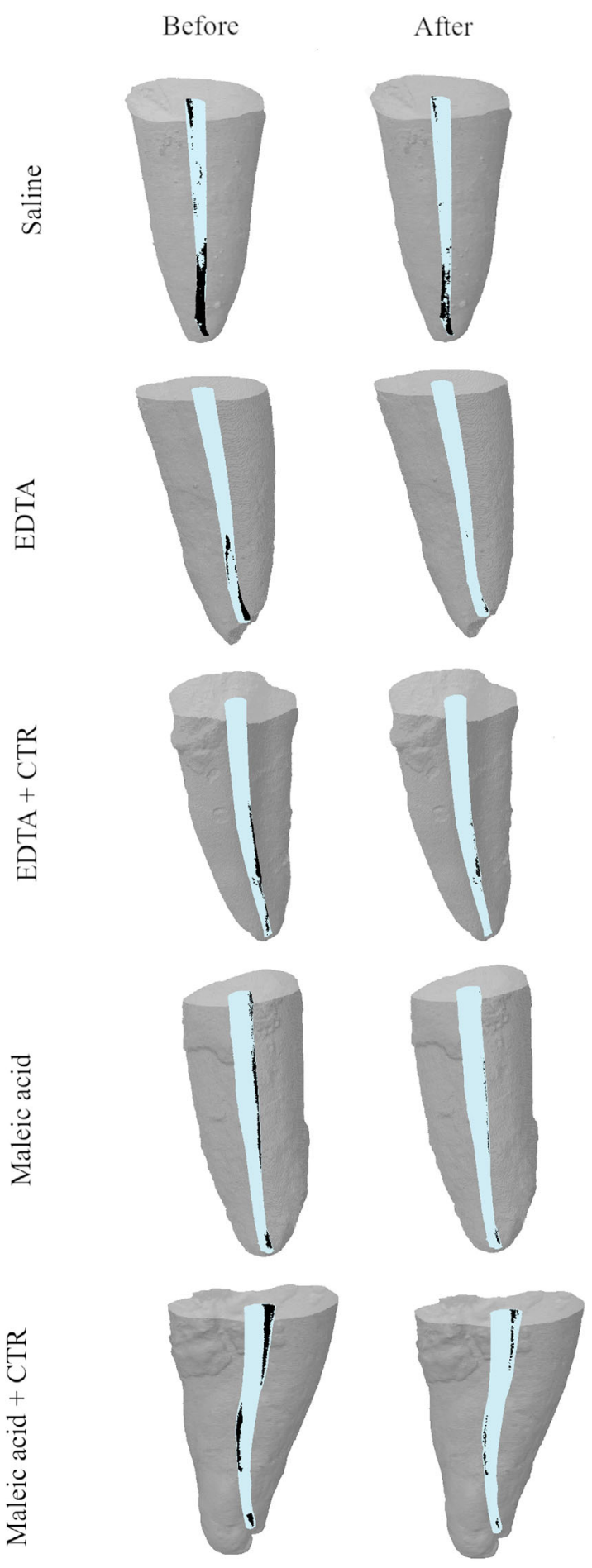

Figure 7 Representative micro-CT reconstructions of the root canal system of the treated teeth before and after the final irrigation with the solutions assigned. Accumulated hard-tissue debris (AHTD) is depicted in black. 
Table 5 Mean values and standard deviations for the percentage of removed accumulated hard-tissue debris (AHTD), and Pvalues of the between-group comparisons (unpaired Student's $t$-test). The among-group comparison (ANova) was significant $(P=0.049)$.

\begin{tabular}{|c|c|c|c|c|c|}
\hline EDTA & EDTA + Cetrimide & Maleic acid & Maleic acid + Cetrimide & saline solution & groups \\
\hline \multirow[t]{5}{*}{$59.7 \pm 20.0$} & $80.85 \pm 7.4$ & $75.6 \pm 21.1$ & $82.1 \pm 14.2$ & $30.6 \pm 20.6$ & \\
\hline & $0.01^{\mathrm{a}}$ & 0.14 & $0.02^{\mathrm{a}}$ & $0.01^{\mathrm{a}}$ & EDTA \\
\hline & & 0.52 & 0.83 & $<0.001^{\mathrm{a}}$ & EDTA + Cetrimide \\
\hline & & & 0.48 & $0.001^{\mathrm{a}}$ & Maleic acid \\
\hline & & & & $<0.001^{\mathrm{a}}$ & Maleic acid + Cetrimide \\
\hline
\end{tabular}

${ }^{\text {a }}$ Statistically significant difference.

\section{Conclusions}

Both final irrigation protocols tested (MA + CTR and EDTA + CTR) had similar effectiveness in the reduction of AHTD from the canal walls and increased their antimicrobial activity when compared to the same solutions without detergents. It was also shown that $7 \%$ MA was less cytotoxic in comparison with $17 \%$ EDTA. However, further in vivo studies need to be performed to confirm the results.

\section{Acknowledgments}

The authors thank Dr. Andrea Venturelli, CEO Simit Dental Mantova, Italy, and Dentsply Sirona Ballaigues, Switzerland, to kindly provide the ProTaper Next rotary files used in the present study.

\section{Conflict of interest}

The authors have stated explicitly that there are no conflicts of interest in connection with this article.

\section{References}

Arias-Moliz MT, Ferrer-Luque CM, Espigares-Rodríguez E, Liébana-Ureña J, Espigares-García M (2008) Bactericidal activity of phosphoric acid, citric acid, and EDTA solutions against Enterococcus faecalis. Oral Surgery, Oral, Medicine, Oral Pathology, Oral Radiology, and Endodontology 106, e84-9.

Arias-Moliz MT, Ferrer-Luque CM, Gonzalez-Rodriguez MP, Valderrama MJ, Baca P (2010) Eradication of Enterococcus faecalis biofilms by cetrimide and chlorhexidine. Journal of Endodontics 36, 87-90.

Baca P, Junco P, Arias-Moliz MT, Castillo F, RodríguezArchilla A, Ferrer-Luque CM (2012) Antimicrobial substantivity over time of chlorhexidine and cetrimide. Journal of Endodontics 38, 927-30.
Bajrami D, Hoxha V, Gorduysus O, Muftuoglu S, Zeybek ND, Küçükkaya S (2014) Cytotoxic effect of endodontic irrigants in vitro. Medical Science Monitor Basic Research 20, 22-6.

Ballal NV, Kundabala M, Bhat S, Rao N, Rao BS (2009a) A comparative in vitro evaluation of cytotoxic effects of EDTA and maleic acid: Root canal irrigants. Oral Surgery, Oral, Medicine, Oral Pathology, Oral Radiology, and Endodontology 108, 633-8.

Ballal NV, Kandian S, Mala K, Bhat KS, Acharya S (2009b) Comparison of the efficacy of maleic acid and ethylenediaminetetraacetic acid in smear layer removal from instrumented human root canal: a scanning electron microscopic study. Journal of Endodontics 35, 1573-6.

Ballal NV, Yegneswaran PP, Mala K, Bhat KS (2011) In vitro antimicrobial activity of maleic acid and ethylenediaminetetraacetic acid on endodontic pathogens. Oral Surgery Oral Medicine Oral Pathology Oral Radiology Endodontology 112, 696-700.

Ballal NV, Ferrer-Luque CM, Sona M, Prabhu KN, AriasMoliz T, Baca P (2018) Evaluation of final irrigation regimens with maleic acid for smear layer removal and wettability of root canal sealer. Acta Odontologica Scandinavica 76, 199-203.

Ballal NV, Jain H, Rao S, Johnson AD, Baeten J, Wolcott JF (2019a) Evaluation of SmearOFF, Maleic acid and two EDTA preparations in smear layer removal from root canal dentin. Acta Odontologica Scandinavica 77, 28-32.

Ballal NV, Das S, Rao BSS, Zehnder M, Mohn D (2019b) Chemical, cytotoxic and genotoxic analysis of etidronate in sodium hypochlorite solution. International Endodontic Journal 52, 1228-34.

Botton G, Pires CW, Cadoná FC et al. (2016) Toxicity of irrigating solutions and pharmacological associations used in pulpectomy of primary teeth. International Endodontic Journal 49, 746-5.

Cavaliere R, Ball JL, Turnbull L, Whitchurch CB (2014) The biofilm matrix destabilizers, EDTA and DNaseI, enhance the susceptibility of nontypeable Hemophilus influenzae biofilms to treatment with ampicillin and ciprofloxacin. Microbiology open 3, 557-67. 
Cergneux M, Ciucchi B, Dietschi JM, Holz J (1987) The influence of the smear layer on the sealing ability of canal obturation. International Endodontic Journal 20, 228-32.

Chávez de Paz LE, Bergenholtz G, Svensäter G (2010) The effects of antimicrobials on endodontic biofilm bacteria. Journal of Endodontics 36, 70-7.

de Almeida J, Hoogenkamp M, Felippe WT, Crielaard W, van der Waal SV (2016) Effectiveness of EDTA and modified salt solution to detach and kill cells from enterococcus faecalis biofilm. Journal of Endodontics 42, 320-3.

De-Deus G, Reis C, Paciornik S (2011) Critical appraisal of published smear layer-removal studies: methodological issues. Oral Surgery, Oral, Medicine, Oral Pathology, Oral Radiology, and Endodontology 112, 531-43.

De-Deus G, Belladonna FG, de Siqueira Zuolo A et al. (2019) Micro-CT comparison of XP-endo Finisher and passive ultrasonic irrigation as final irrigation protocols on the removal of accumulated hard-tissue debris from oval shaped-canals. Clinical Oral Investigations 23, 3087-93.

Dunavant TR, Regan JD, Glickman GN, Solomon ES, Honeyman AL (2006) Comparative evaluation of endodontic irrigants against Enterococcus faecalis biofilms. Journal of Endodontics 32, 527-31.

Ferrer-Luque CM, Arias-Moliz MT, Gonzalez-Rodrıguez MP, Baca P (2010) Antimicrobial activity of maleic acid and combinations of cetrimide with chelating agents against Enterococcus faecalis biofilm. Journal of Endodontics 36, $1673-5$.

Franken NA, Rodermond HM, Stap J, Haveman J, van Bree C (2006) Clonogenic assay of cells in vitro. Nature Protocols 1, 2315-9.

Gettleman BH, Messer HH, El Deeb ME (1991) Adhesion of sealer cements to dentine with and without the smear layer. Journal of Endodontics 17, 15-20.

Giardino L, Ambu E, Becce C, Rimondini L, Morra M (2006) Surface tension comparison of four common root canal irrigants and two new irrigants containing antibiotic. Journal of Endodontics 32, 1091-3.

Giardino L, Cavani F, Generali L. (2017) Sodium hypochlorite solution penetration into human dentine: a histochemical evaluation. International Endodontic Journal 50, 492-8.

Giardino L, Del Fabbro M, Cesario F, Fernandes FS, Andrade FB (2018) Antimicrobial effectiveness of combinations of oxidant and chelating agents in infected dentine: an ex vivo confocal laser scanning microscopy study. International Endodontic Journal 51, 448-56.

Heling I, Irani E, Karni S, Steinberg D (1999) In vitro antimicrobial effect of RC-Prep within dentinal tubules. Journal of Endodontics 25, 782-5.

Jaiswal S, Patil V, Satish Kumar KS, Ratnakar P, Rairam S, Tripathi S (2018) Comparative analysis of smear layer removal by conventional endodontic irrigants with a newly experimented irrigant-fumaric acid: A scanning electron microscopic study. Journal of Conservative Dentistry 21, 419-23.
Keleş A, Alçin H, Sousa-Neto MD, Versiani MA (2016) Supplementary steps for removing hard tissue debris from isthmus-containing canal systems. Journal of Endodontics 42, 1677-82.

Labban N, Yassen GH, Windsor LJ, Platt JA (2014) The direct cytotoxic effects of medicaments used in endodontic regeneration on human dental pulp cells. Dental Traumatology 30, 429-34.

Liu Y, Guo L, Li Y, Guo X, Wang B, Wu L (2015) In vitro comparison of antimicrobial effectiveness of QMix and other final irrigants in human root canals. Scientific Reports 3(5), 17823. https://doi.org/10.1038/srep17823. $5: 17823$.

Malheiros CF, Marques MM, Gavini G (2005) In vitro evaluation of the cytotoxic effects of acid solutions used as canal irrigants. Journal of Endodontics 31, 746-8.

McComb D, Smith DC (1975) A preliminary scanning electron microscopic study of root canals after endodontic procedures. Journal of Endodontics 1, 238-42.

Mosmann T (1983) Rapid colorimetric assay for cellular growth and survival: application to proliferation and cytotoxicity assays. Journal of Immunological Methods 65, 5563.

Nersesyan A, Fenech M, Bolognesi C et al. (2016) Use of the lymphocyte cytokinesis-block micronucleus assay in occupational biomonitoring of genome damage caused by in vivo exposure to chemical genotoxins: Past, present and future. Mutation Research 770, 1-11.

O'Connell MS, Morgan LA, Beeler WJ, Baumgartner JC (2000) A comparative study of smear layer removal using different salts of EDTA. Journal of Endodontics 26, 739-43.

Ordinola-Zapata R, Bramante CM, Cavenago B et al. (2012) Antimicrobial effect of endodontic solutions used as final irrigants on a dentine biofilm model. International Endodontic Journal 45, 162-8.

Ørstavik D, Haaapasalo M (1990) Disinfection by endodontic irrigants and dressings of experimentally infected dentinal tubules. Endodontic Dental Traumatology 6, 142-9.

Paqué F, Laib A, Gautschi H, Zehnder M (2009) Hard-tissue debris accumulation analysis by high-resolution computed tomography scans. Journal of Endodontics 35, 1044-7.

Peters OA (2013) Research that matters - biocompatibility and cytotoxicity screening. International Endodontic Journal 46, 195-7.

Peters OA, Boessler C, Paqué F (2010) Root canal preparation with a novel nickel-titanium instrument evaluated with micro-computed tomography: canal surface preparation over time. Journal of Endodontics 36, 1068-72.

Puck TT, Marcus PI (1955) A rapid method for viable cell titration and clone production with HeLa cells in tissue culture: the use of X-irradiated cells to supply conditioning factors. Proceedings of the National Academy of Sciences 41, 432-437.

Reidmiller JS, Smith WL, Sawyer MM, Osburn BI, Stott JL, Cullor JS (2006) Antimicrobial properties of the chelating 
agent EDTA on Streptococcal bovine mastitis isolates. Journal of Food Protection 69, 1460-2.

Roy R, Tiwari M, Donelli G, Tiwari V (2018) Strategies for combating bacterial biofilms: A focus on anti-biofilm agents and their mechanisms of action. Virulence 9, 522554.

Segura JJ, Calvo JR, Guerrero JM, Sampedro C, Jimenez A, Llamas R (1996) The disodium salt of EDTA inhibits the binding of vasoactive intestinal peptide to macrophage membranes: Endodontic implications. Journal of Endodontics 22, 337-40.

Shahravan A, Haghdoost A, Adl A, Rahimi H, Shadifar F (2007) Effect of smear layer on sealing ability of canal obturation: a systematic review and meta-analysis. Journal of Endodontics 33, 96-105.

Silva EJNL, Carvalho CR, Belladonna FG et al. (2019) MicroCT evaluation of different final irrigation protocols on the removal of hard-tissue debris from isthmus-containing mesial root of mandibular molars. Clinical Oral Investigations 23, 681-687.

Simões M, Pereira MO, Vieira MJ (2005) Effect of mechanical stress on biofilms challenged by different chemicals. Water Research 39, 5142-52.

Stuart CH, Schwartz SA, Beeson TJ, Owatz CB (2006) Enterococcus faecalis: its role in root canal treatment failure and current concepts in retreatment. Journal of Endodontics 32, 93-8.

Tay FR, Gu LS, Schoeffel GJ et al. (2010) Effect of vapor lock on root canal debridement by using a side-vented needle for positive-pressure irrigant delivery. Journal of Endodontics 36, 745-50.
Teixeira CS, Felippe MC, Felippe WT (2005) The effect of application time of EDTA and $\mathrm{NaOCl}$ on intracanal smear layer removal: an SEM analysis. International Endodonticjournal 38, 285-90.

Torabinejad M, Handysides R, Khademi AA, Bakland LK (2002) Clinical implications of the smear layer in endodontics: a review. Oral Surgery Oral Medicine Oral Pathology Oral Radiology Endodontology 94, 658-6.

Ulusoy ÖI, Görgül G (2013) Effects of different irrigation solutions on root dentine microhardness, smear layer removal and erosion. Australian Endodontic Journal 39, 66-72.

Versiani MA, Pereira MR, Pécora JD, Sousa-Neto MD. (2019) Root Canal Anatomy of Maxillary and Mandibular Teeth. In: Versiani M, Basrani B, Sousa-Neto M, eds. The Root Canal Anatomy in Permanent Dentition. Cham, Switzerland: Springer, pp. 181-97.

Wang Z, Shen Y, Ma J, Haapasalo M (2012) The effect of detergents on the antibacterial activity of disinfecting solutions in dentin. Journal of Endodontics 38, 948-53.

White RR, Goldman M, Lin PS (1984) The influence of the smeared layer upon dentinal tubule penetration by plastic filling materials. Journal of Endodontics 10, 558-62.

Yilmaz Z, Basbag B, Buzoglu HD, Gümüsderelioglu M (2011) Effect of low-surface-tension EDTA solutions on the wettability of root canal dentin. Oral Surgery Oral Medicine Oral Pathology Oral Radiology and Endodontology 111, 109-14.

Zehnder M (2006) Root canal irrigants. Journal of Endodontics 32, 389-98.

Zehnder M, Schmidlin P, Sener B, Waltimo T (2005) Chelation in root canal therapy reconsidered. Journal of Endodontics 31, 817-20. 